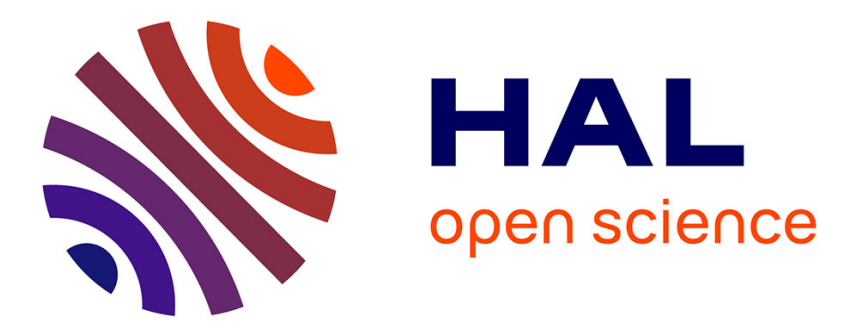

\title{
Estrogen receptor alpha gene variants and major depressive episodes.
}

Joanne Ryan, Jacqueline Scali, Isabelle Carrière, Karine Peres, Olivier

Rouaud, Pierre-Yves Scarabin, Karen Ritchie, Marie-Laure Ancelin

\section{To cite this version:}

Joanne Ryan, Jacqueline Scali, Isabelle Carrière, Karine Peres, Olivier Rouaud, et al.. Estrogen receptor alpha gene variants and major depressive episodes.. Journal of Affective Disorders, 2012, 136 (3), pp.1222-6. 10.1016/j.jad.2011.10.010 . inserm-00856844

\section{HAL Id: inserm-00856844 https://www.hal.inserm.fr/inserm-00856844}

Submitted on 2 Sep 2013

HAL is a multi-disciplinary open access archive for the deposit and dissemination of scientific research documents, whether they are published or not. The documents may come from teaching and research institutions in France or abroad, or from public or private research centers.
L'archive ouverte pluridisciplinaire HAL, est destinée au dépôt et à la diffusion de documents scientifiques de niveau recherche, publiés ou non, émanant des établissements d'enseignement et de recherche français ou étrangers, des laboratoires publics ou privés. 


\section{Estrogen receptor alpha gene variants and major depressive episodes}

Joanne Ryan a,b,c,*, Jacqueline Scali ${ }^{\text {a,b }}$, Isabelle Carrière ${ }^{\text {a,b }}$, Karine Peres ${ }^{\mathrm{d}}$, Olivier Rouaud ${ }^{\mathrm{e}}$, Pierre-Yves Scarabin ${ }^{\mathrm{f}}$, Karen Ritchie ${ }^{\mathrm{a}, \mathrm{b}, \mathrm{g}}$, Marie-Laure Ancelin ${ }^{\mathrm{a}, \mathrm{b}}$

${ }^{a}$ Inserm, U 1061, Hopital La Colombiere, Montpellier, F-34093 France;

${ }^{\mathrm{b}}$ University Montpellier 1, Montpellier, F-34000 France;

${ }^{c}$ Fondation FondaMental, Hopital Albert Chenevier, 40 rue de Mesly, 94000 Creteil, France;

${ }^{\mathrm{d} I n s e r m, ~ U 897, ~ U n i v e r s i t y ~ B o r d e a u x ~ 2, ~} 33076$ Bordeaux, France;

${ }^{e}$ Centre Mémoire Ressources et Recherche, Centre Hospitalier Universitaire, Dijon, France;

${ }^{\mathrm{f}}$ Inserm, U1018, Université Paris Sud 11, F-94807 Villejuif, France;

${ }^{g}$ Faculty of Medicine, Imperial College, SW7 2AZ London, United Kingdom.

*Corresponding author: Inserm U1061, Hopital La Colombiere P42, 39 avenue Charles Flahault BP 34493, 34093 Montpellier Cedex 5, France. Tel : +33 499614 565; Fax : +33499614579.

E-mail address: joanne.ryan@inserm.fr (J. Ryan). 


\section{ABSTRACT}

Background: Despite evidence of estrogen's mood-enhancing effects, the association between estrogen receptor (ER) gene variants and lifetime major depression has been insufficiently studied.

Methods: 3987 community-dwelling women aged 65 years and over were recruited in France as part of the Three City Study. Current and past major depressive disorders (MDD) were diagnosed using the Mini-International Neuropsychiatry Interview, according to DSM-IV criteria. The association between two common estrogen receptor alpha (ESR1) polymorphisms with lifetime MDD was examined using adjusted logistic regression models, taking into account the age at first depressive episode and the recurrence of depression.

Results: Women homozygous for the variant G allele of ESR1 rs9340799 had a 1.6-fold increased risk of MDD across their lifetime compared with women who were homozygous for the A allele $(\mathrm{p}=0.009)$. There was a similar non-significant trend for the $\mathrm{C}$ allele of $r s 2234693$ being associated with an increased risk $(\mathrm{p}=0.09)$. Polytomous regression analysis further indicated that the GG genotype of $r s 9340799$ was specifically associated with an increased risk of recurrent depressive episodes, regardless of the age at first onset of depression relative to the menopause.

Limitations: The duration and severity of depressive episodes was not considered in the analysis.

Conclusions: This is the first study to examine the association between ESR1 gene variants and lifetime MDD. Our findings indicate a significant association between common variants and the risk of recurrent depressive episodes. This suggests that certain depressed women could be most responsive to hormone-based treatment.

Key words: estrogen receptor polymorphisms; major depressive disorder; recurrent depressive episodes; elderly women 


\section{Introduction}

There is considerable evidence in support of estrogen's mood enhancing effects. Estrogen can enhance serotonergic activity by regulating the synthesis and degradation of serotonin (McEwen and Alves, 1999; Osterlund, 2010), and short-term randomised controlled trials have demonstrated the efficacy of estradiol in improving the mood of depressed perimenopausal, but not necessarily postmenopausal, women (Cohen et al., 2003; Schmidt et al., 2000; Soares et al., 2001). Variations in estrogen signalling may therefore modify a person's risk of depression.

Estrogen exerts its biological actions in large part through intracellular action of its receptors (ERs), with the estrogen-ER complex able to influence the transcription of hundreds of genes (Chen et al., 2008). We have previously reported a highly significant association between two common single nucleotide polymorphisms (SNPs) in the ER-alpha (ESR1) and the risk of current depressive symptoms in older women, with no such association in men (Ryan et al., 2011a). The very small number of other studies however, which have investigated the association between ER gene variants and depression risk have reported mixed findings and this may relate to heterogeneity in terms of the populations studied (i.e. their age and menopausal status) and the form of depression actually been measured. Here we aimed to investigate further the role of these ESR1 polymorphisms in depression by examining major depressive disorder (MDD) across the entire lifetime. Prior studies suggest that recurrent depression in particular may have a large genetic component (see for review (Burcusa and Iacono, 2007)), and we therefore focused on potential differential associations of these ESR1 variants with women reporting single vs. multiple depressive episodes. Furthermore, as our previous work suggested ESR1 polymorphisms were specifically associated with late-life depressive symptoms in women only, and as a decline in estrogen levels accompanies the menopause, we also examined whether these ESR1 gene variants were differentially associated with depression onset before or after the menopause.

\section{Methods}

\subsection{Participants}

Community-dwelling participants aged 65 years and over were randomly selected from the

electoral rolls in France as part of the Three City longitudinal study (The 3C Study Group, 2003). 
The study protocol was approved by the Ethical Committee of the University Hospital of Kremlin-Bicêtre (France) and participants provided written informed consent.

This analysis is based on 3987 of the 5524 dementia-free women initially recruited to the 3C Study. Participants were excluded from this analysis if they did not provide blood samples or had incomplete genotyping data $(n=544)$, if they did not undergo psychiatric assessment $(n=640)$, if they failed to provide details of past depressive episodes $(n=203)$ or if they did not record their use of hormone treatment $(n=150)$. Excluded participants were more likely to have a lifetime $\operatorname{MDD}\left(\chi_{2}^{2}=320, \mathrm{p}<0.0001\right)$, but there was no significant difference in terms of the distribution of ER genotypes.

\subsection{Procedures}

Participants were administered interviews by trained staff to obtain socio-demographic, health and lifestyle information. Age at menopause was defined as one year without menses or following self-reported bilateral oophorectomy, with or without hysterectomy. All types of medication used during the preceding month (including hormone treatment and antidepressants) were validated by presentation of the prescription or the medication itself. Current and past MDD were diagnosed according to the Diagnostic and Statistical Manual of Mental Disorders (DSM-IV) criteria using the Mini-International Neuropsychiatry Interview (MINI), a standardized psychiatric examination which has been validated in the general elderly population (Sheehan et al., 1998). Participants also recorded the number of prior depressive episodes and the age at which their first episode occurred.

Genotyping was performed on DNA extracted from white blood cells by Kbiosciences (Hoddesdon Herts, UK) using their competitive allele-specific PCR SNP genotyping system (KASPar) which has an error rate of <0.3\%. Two ESR1 SNPs located at position 397 and 351 of intron 1 were examined, rs9340799 and rs2234693 respectively. These SNPs were chosen for because: 1/ they have shown potential causal associations with other estrogen-dependent health outcomes, including Alzheimer's disease (Corbo et al., 2006), cognitive function (Yaffe et al., 2002), cardiovascular disease (Herrington et al., 2002; Shearman et al., 2003), osteoporosis (Ioannidis et al., 2002), breast cancer (Kjaergaard et al., 2007; Slattery et al., 2007) and vasomotor symptoms (Malacara et al., 2004); 2/ we have previously demonstrated significant associations between these ESR1 polymorphisms and depressive symptoms in older women 
(Ryan et al., 2011a); 3/ there is evidence that these polymorphisms are functional as they regulate ESR1 expression (Alonso et al., 2011; Herrington et al., 2002; Maruyama et al., 2000) and have shown some association serum estradiol levels (Schuit et al., 2005; Sowers et al., 2006).

\subsection{Statistical Analysis}

A $\chi^{2}$ test was used to compare the observed allele frequencies with those expected under the Hardy-Weinberg equilibrium. Logistic regression models were used to determine the association between ESR1 polymorphisms and lifetime MDD assuming an additive model. Women were then classified into one of the following four subgroups based on their age at onset of MDD relative to the menopause and the number of lifetime MDDs: a single MDD episode occurring before menopause; a single MDD episode occurring at or after the menopause; two or more MDD episodes with first onset occurring before the menopause; and two or more MDD episodes with first onset occurring at or after the menopause. Polytomous regression was employed to examine the differential associations between ESR1 polymorphisms and these subgroups. Models adjusted for age, highest level of education attained, recruitment centre, use of hormone treatment, antidepressant use and bilateral oophorectomy occurring before the age at natural menopause. SAS version 9.1 (SAS Institute, Inc., Cary, North Carolina) was used for all of the analyses and all tests were two-tailed with a significance level of $\mathrm{p}<0.05$.

\section{Results}

Women in this study ranged from 65 to 96 years of age, with a median of 73 years (interquartile range: $70-77)$ and almost a quarter (24.2\%) reported more than 12 years of education. The median age at menopause was 50 years (interquartile range: 47-53). Overall 466 participants were diagnosed with a MDD across the lifetime, with a higher percentage of past $(9.5 \%)$ compared to current episodes (2.0\%). Of these women, 246 reported that their first MDD occurred before their menopause, with the remaining 220 stating it occurred during or after the menopause. There were similar numbers of women who reported a single MDD $(n=250)$ and multiple episodes across their lifetime $(n=216)$. Overall, $8.0 \%$ of the participants reported current antidepressant use. 
The ESR1 genotype frequencies in this population (Table 1) were not significantly different from those predicted by the Hardy-Weinberg equilibrium $\left(\chi^{2}{ }_{1}=3.3, p=0.07\right.$ and $\chi^{2}{ }_{1}=1.6$, $\mathrm{p}=0.21$ respectively). The SNPs were in strong linkage disequilibrium $\left(\left|\mathrm{D}^{\prime}\right|=0.98\right)$. After controlling for age, highest education level attained, recruitment centre, use of hormone treatment, antidepressant use and bilateral oophorectomy, logistic regession analysis indicated that women with the GG allele of $r s 9340799$ had a 1.6-fold increased risk of MDD compared to women who were homozygous for the A allele. Women who were heterozygote GA were not at a significantly increased risk. There was a similar although non-significant trend for $r s 2234693$, where women homozygous for the $\mathrm{C}$ allele had an increased risk compared to women with the TT genotype. The polytomous regression model (Table 2) indicated that the GG genotype of rs9340799 was associated with a significantly increased risk of two or more MDDs, regardless of the age at first onset of depression relative to the menopause. Women with the CC genotype of rs2234693 compared to those TT, had a significantly increased risk of multiple depressive episodes occuring during the post-menopause.

\section{Discussion}

There is evidence that the $r s 9340799$ and $r s 2234693$ SNPs may be functionally significant as they have been shown to regulate the expression of the ESR1 and alter transcription factor binding (Herrington et al., 2002; Maruyama et al., 2000). The G and C alleles respectively have been associated with higher gene expression (Alonso et al., 2011), and increased serum estrogen levels (Schuit et al., 2005; Sowers et al., 2006), although not consistently (Malacara et al., 2004; Yaffe et al., 2009). In a similar manner, one or both alleles have also been associated with more favourable estrogen-dependent outcomes such as higher bone mass density and lower fractures (Ioannidis et al., 2002)), and a decreased risk of cognitive impairment (Yaffe et al., 2002), Alzheimer's disease (Monastero et al., 2006), phobia (Ryan et al., 2011b), general anxiety (Tiemeier et al., 2005) and cardiovascular disease (Schuit et al., 2004). On the other hand, other studies have also reported both null (den Heijer et al., 2004; Koch et al., 2005; Silvestri et al., 2006) and reverse findings (Brandi et al., 1999; Shearman et al., 2003). Given the reported mood-enhancing effects of estrogen treatment, at least when given to perimenopausal women (Cohen et al., 2003; Schmidt et al., 2000; Soares et al., 2001), these ESR1 gene variants might 
therefore be expected to reduce the risk of depression, but this could also vary relative to the menopause.

This current analysis however, has revealed that the $\mathrm{G}$ and $\mathrm{C}$ alleles of rs9340799 and rs2234693 were associated with an increased risk of lifetime MDD. The only other study to examine the association between ER polymorphisms and MDD supports these findings, in that the frequency of the $r s 234693 \mathrm{CC}$ genotype was significantly higher in 126 midlife Chinese women compared to the 89 controls (Tsai et al., 2003). When we examined in further detail lifetime MDD, our results showed that both ESR1 gene variants were most strongly associated with recurrent depressive episodes occurring after the menopause. In terms of the GG genotype of $r s 9340799$, there was also a significant increased risk of recurrent episodes with onset before the menopause but there was no association between these SNPs and single depressive episodes. In analyses adjusted for past MDD, we have previously reported that older postmenopausal women (mean age 73.5 years) with current depressive symptomatology (measured using the Centre for Epidemiological Studies - Depression Scale, CES-D (Radloff, 1977)), were less likely to carry the $\mathrm{G}$ and $\mathrm{C}$ alleles of $r s 9340799$ and $r s 2234693$ respectively (Ryan et al., 2011a). The exact reasons for these discrepancies remain to be elucidated. At least in terms of the rs9340799, this ESR1 gene variant may be differentially associated with recurrent MDD across the lifetime compared to symptoms of depression which occur for the first time in later-life. Given (i) the genetic heterogeneity of MDD (Levinson, 2006); (ii) the different aetiologies of early and lateonset depression, with notably a later age at onset for vascular depression (Blazer, 2003; Kendler et al., 2009); (iii) the potentially atherogenic aetiology of depression in older women (Ancelin et al., 2010); (iv) the suspected involvement of steroids and ESR1 in cardiovascualar disease; (v) the prior identification of risk factors which are specific to recurrent depression (Burcusa and Iacono, 2007; Lewinsohn et al., 1999); and (vi) the fact that depression is a multi-factorial disease likely to be caused by a number of environmental, biological and genetic factors with varying interactions across the lifespan, it seems conceivable that certain steroid-related genes may be differentially associated with specific forms of depression (Harro and Kiive, 2011). Furthermore, as the ESR1 acts as a ligand-activated transcription factor affecting hundreds of genes, including regulating the synthesis and metabolism of various neurotransmitters in the brain (McEwen and Alves, 1999), the exact mechanisms by which ESR1 variants could influence depression are complex. These SNPs may also be in linkage disequilibrium with yet 
unidentified functional ESR1 polymorphisms. This may also help to explain the differential associations between these SNPs and depression, as well as the heterogeneity in results from prior studies investigating ER polymorphisms and other health-related outcomes.

This study is strengthened by its sample size and population-based design. MDD was assessed by trained staff using a structured diagnostic interview according to DSM-IV criteria, which has been validated in the general population (Sheehan et al., 1998). Study limitations include the possibility of population stratification which we could not control for because French law prohibits the collection of ethnic-related data, however genotype frequencies are similar to those observed in Caucasian populations (Ioannidis et al., 2002). We did not consider the duration or severity of depressive episodes which may have influenced the results and it remains possible that the associations reported here can be explained by other unknown factors.

Our findings suggest the ESR1 may play a particularly important role in recurrent depression, with certain women being genetically more susceptible to multiple depressive episodes across their lifetime. Given that recurrent depression is associated with significantly higher comorbidity than single episodes (Gili et al., 2011), this emphasises the importance of identifying specific risk factors. These results highlight the potential for developing novel ERtargeted hormone treatments for sub-groups of women most at risk of recurrent MDD, but further studies examining the association between the ESR1 and MDD across the lifetime are needed to help confirm our findings. 


\section{References}

Alonso, P., Gratacos, M., Segalas, C., Escaramis, G., Real, E., Bayes, M., Labad, J., Pertusa, A., Vallejo, J., Estivill, X., Menchon, J.M., 2011. Variants in estrogen receptor alpha gene are associated with phenotypical expression of obsessive-compulsive disorder. Psychoneuroendocrinology 36, 473-483.

Ancelin, M.L., Carrière, I., Boulenger, J.P, Malafosse, A., Stewart, R., Cristol, J.P., Ritchie, K., Chaudieu, I., Dupuy, A.M., 2010. Gender and genotype modulation of the association between lipid levels and depressive symptomatology in community-dwelling elderly (the ESPRIT study). Biol Psychiatry. 68, 125-32.

Blazer, D.G., 2003. Depression in late life: review and commentary. J Gerontol A Biol Sci Med Sci 58, 249-265.

Brandi, M.L., Becherini, L., Gennari, L., Racchi, M., Bianchetti, A., Nacmias, B., Sorbi, S.,

Mecocci, P., Senin, U., Govoni, S., 1999. Association of the estrogen receptor alpha gene polymorphisms with sporadic Alzheimer's disease. Biochem Biophys Res Commun 265, 335338.

Burcusa, S.L., Iacono, W.G., 2007. Risk for recurrence in depression. Clin Psychol Rev 27, 959985.

Chen, G.G., Zeng, Q., Tse, G.M., 2008. Estrogen and its receptors in cancer. Med Res Rev 28, 954-974.

Cohen, L.S., Soares, C.N., Poitras, J.R., Prouty, J., Alexander, A.B., Shifren, J.L., 2003. Shortterm use of estradiol for depression in perimenopausal and postmenopausal women: a preliminary report. Am J Psychiatry 160, 1519-1522.

Corbo, R.M., Gambina, G., Ruggeri, M., Scacchi, R., 2006. Association of Estrogen Receptor alpha (ESR1) PvuII and XbaI Polymorphisms with Sporadic Alzheimer's Disease and Their Effect on Apolipoprotein E Concentrations. Dement Geriatr Cogn Disord 22, 67-72.

den Heijer, T., Schuit, S.C., Pols, H.A., van Meurs, J.B., Hofman, A., Koudstaal, P.J., van Duijn, C.M., Uitterlinden, A.G., Breteler, M.M., 2004. Variations in estrogen receptor alpha gene and risk of dementia, and brain volumes on MRI. Mol Psychiatry 9, 1129-1135. 
Gili, M., Garcia-Toro, M., Vives, M., Armengol, S., Garcia-Campayo, J., Soriano, J.B., Roca, M., 2011. Medical comorbidity in recurrent versus first-episode depressive patients. Acta Psychiatr Scand 123, 220-227.

Harro, J., Kiive, E., 2011. Droplets of black bile? Development of vulnerability and resilience to depression in young age. Psychoneuroendocrinology 36, 380-392.

Herrington, D.M., Howard, T.D., Brosnihan, K.B., McDonnell, D.P., Li, X., Hawkins, G.A., Reboussin, D.M., Xu, J., Zheng, S.L., Meyers, D.A., Bleecker, E.R., 2002. Common estrogen receptor polymorphism augments effects of hormone replacement therapy on E-selectin but not C-reactive protein. Circulation 105, 1879-1882.

Ioannidis, J.P., Stavrou, I., Trikalinos, T.A., Zois, C., Brandi, M.L., Gennari, L., Albagha, O., Ralston, S.H., Tsatsoulis, A., 2002. Association of polymorphisms of the estrogen receptor alpha gene with bone mineral density and fracture risk in women: a meta-analysis. J Bone Miner Res 17, 2048-2060.

Kendler, K.S., Fiske, A., Gardner, C.O., Gatz, M., 2009. Delineation of two genetic pathways to major depression. Biol Psychiatry 65, 808-811.

Kjaergaard, A.D., Ellervik, C., Tybjaerg-Hansen, A., Axelsson, C.K., Gronholdt, M.L., Grande, P., Jensen, G.B., Nordestgaard, B.G., 2007. Estrogen receptor alpha polymorphism and risk of cardiovascular disease, cancer, and hip fracture: cross-sectional, cohort, and case-control studies and a meta-analysis. Circulation 115, 861-871.

Koch, W., Hoppmann, P., Pfeufer, A., Mueller, J.C., Schomig, A., Kastrati, A., 2005. No replication of association between estrogen receptor alpha gene polymorphisms and susceptibility to myocardial infarction in a large sample of patients of European descent. Circulation 112, 2138-2142.

Levinson, D.F., 2006. The genetics of depression: a review. Biol Psychiatry 60, 84-92.

Lewinsohn, P.M., Allen, N.B., Seeley, J.R., Gotlib, I.H., 1999. First onset versus recurrence of depression: differential processes of psychosocial risk. J Abnorm Psychol 108, 483-489.

Malacara, J.M., Perez-Luque, E.L., Martinez-Garza, S., Sanchez-Marin, F.J., 2004. The relationship of estrogen receptor-alpha polymorphism with symptoms and other characteristics in post-menopausal women. Maturitas 49, 163-169.

Maruyama, H., Toji, H., Harrington, C.R., Sasaki, K., Izumi, Y., Ohnuma, T., Arai, H., Yasuda, M., Tanaka, C., Emson, P.C., Nakamura, S., Kawakami, H., 2000. Lack of an association of 
estrogen receptor alpha gene polymorphisms and transcriptional activity with Alzheimer disease. Arch Neurol 57, 236-240.

McEwen, B.S., Alves, S.E., 1999. Estrogen actions in the central nervous system. Endocr Rev 20, 279-307.

Monastero, R., Cefalu, A.B., Camarda, C., Noto, D., Camarda, L.K., Caldarella, R., Imbornone, E., Averna, M.R., Camarda, R., 2006. Association of estrogen receptor alpha gene with Alzheimer's disease: a case-control study. J Alzheimers Dis 9, 273-278.

Osterlund, M.K., 2010. Underlying mechanisms mediating the antidepressant effects of estrogens. Biochim Biophys Acta 1800, 1136-1144.

Radloff, L., 1977. The CES-D scale: a self-report depression scale for research in the general population. Appl Psychol Measurement 1, 385-401.

Ryan, J., Scali, J., Carriere, I., Peres, K., Rouaud, O., Scarabin, P.Y., Ritchie, K., Ancelin, M.L., 2011a. Oestrogen receptor polymorphisms and late-life depression. Br J Psychiatry 199, 126131.

Ryan, J., Scali, J., Carriere, I., Scarabin, P.Y., Ritchie, K., Ancelin, M.L., 2011b. Estrogen receptor gene variants are associated with anxiety disorders in older women. Psychoneuroendocrinology.

Schmidt, P.J., Nieman, L., Danaceau, M.A., Tobin, M.B., Roca, C.A., Murphy, J.H., Rubinow, D.R., 2000. Estrogen replacement in perimenopause-related depression: a preliminary report. Am. J. Obstet. Gynecol. 183, 414-420.

Schuit, S.C., de Jong, F.H., Stolk, L., Koek, W.N., van Meurs, J.B., Schoofs, M.W., Zillikens, M.C., Hofman, A., van Leeuwen, J.P., Pols, H.A., Uitterlinden, A.G., 2005. Estrogen receptor alpha gene polymorphisms are associated with estradiol levels in postmenopausal women. Eur J Endocrinol 153, 327-334.

Schuit, S.C., Oei, H.H., Witteman, J.C., Geurts van Kessel, C.H., van Meurs, J.B., Nijhuis, R.L., van Leeuwen, J.P., de Jong, F.H., Zillikens, M.C., Hofman, A., Pols, H.A., Uitterlinden, A.G., 2004. Estrogen receptor alpha gene polymorphisms and risk of myocardial infarction. Jama 291, 2969-2977.

Shearman, A.M., Cupples, L.A., Demissie, S., Peter, I., Schmid, C.H., Karas, R.H., Mendelsohn, M.E., Housman, D.E., Levy, D., 2003. Association between estrogen receptor alpha gene variation and cardiovascular disease. Jama 290, 2263-2270. 
Sheehan, D.V., Lecrubier, Y., Sheehan, K.H., Amorim, P., Janavs, J., Weiller, E., Hergueta, T., Baker, R., Dunbar, G.C., 1998. The Mini-International Neuropsychiatric Interview (M.I.N.I.): the development and validation of a structured diagnostic psychiatric interview for DSM-IV and ICD-10. J Clin Psychiatry 59, 22-33;quiz 34-57.

Silvestri, S., Thomsen, A.B., Gozzini, A., Bagger, Y., Christiansen, C., Brandi, M.L., 2006. Estrogen receptor alpha and beta polymorphisms: is there an association with bone mineral density, plasma lipids, and response to postmenopausal hormone therapy? Menopause 13, 451461.

Slattery, M.L., Sweeney, C., Herrick, J., Wolff, R., Baumgartner, K., Giuliano, A., Byers, T., 2007. ESR1, AR, body size, and breast cancer risk in Hispanic and non-Hispanic white women living in the Southwestern United States. Breast Cancer Res Treat 105, 327-335.

Soares, C.N., Almeida, O.P., Joffe, H., Cohen, L.S., 2001. Efficacy of estradiol for the treatment of depressive disorders in perimenopausal women: a double-blind, randomized, placebocontrolled trial. Arch. Gen. Psychiatry. 58, 529-534.

Sowers, M.R., Wilson, A.L., Karvonen-Gutierrez, C.A., Kardia, S.R., 2006. Sex steroid hormone pathway genes and health-related measures in women of 4 races/ethnicities: the Study of Women's Health Across the Nation (SWAN). Am J Med 119, S103-110.

The 3C Study Group, 2003. Vascular factors and risk of dementia: Design of the three city study and baseline characteristics of the study population. Neuroepidemiology 22, 316-325.

Tiemeier, H., Schuit, S.C., den Heijer, T., van Meurs, J.B., van Tuijl, H.R., Hofman, A., Breteler, M.M., Pols, H.A., Uitterlinden, A.G., 2005. Estrogen receptor alpha gene polymorphisms and anxiety disorder in an elderly population. Mol Psychiatry 10, 806-807.

Tsai, S.J., Wang, Y.C., Hong, C.J., Chiu, H.J., 2003. Association study of oestrogen receptor alpha gene polymorphism and suicidal behaviours in major depressive disorder. Psychiatr Genet $13,19-22$.

Yaffe, K., Lindquist, K., Sen, S., Cauley, J., Ferrell, R., Penninx, B., Harris, T., Li, R., Cummings, S.R., 2009. Estrogen receptor genotype and risk of cognitive impairment in elders: findings from the Health ABC study. Neurobiol Aging 30, 607-614.

Yaffe, K., Lui, L.Y., Grady, D., Stone, K., Morin, P., 2002. Estrogen receptor 1 polymorphisms and risk of cognitive impairment in older women. Biol Psychiatry 51, 677-682. 


\section{Table 1:}

Adjusted $^{\mathrm{a}}$ logistic regression analysis for the association between ESR1 polymorphisms and major depressive episodes ${ }^{\mathrm{b}}(\mathrm{N}=3987)$.

\begin{tabular}{llll}
\hline \multirow{2}{*}{ SNP } & Genotype & $\mathrm{N}$ & $\begin{array}{l}\text { Risk of Lifetime MDD } \\
\text { Odds Ratio (95\% CI), } p\end{array}$ \\
\hline$r s 9340799$ & AA & 1656 & 1 \\
& GA & 1867 & $1.07(0.85-1.35), 0.59$ \\
& GG & 464 & $1.57(1.12-2.19), 0.009$ \\
$r s 2234693$ & TT & 1201 & 1 \\
& CT & 2010 & $1.05(0.82-1.36), 0.70$ \\
& CC & 776 & $1.30(0.96-1.77), 0.09$ \\
\hline
\end{tabular}

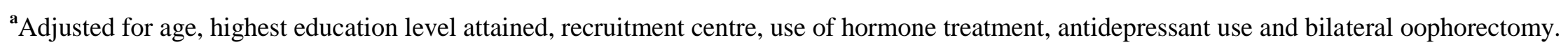

${ }^{\mathbf{b}}$ With reference to women without any major depressive episodes across their lifetime $(\mathrm{n}=3521)$. 
Table 2:

Adjusted $^{\mathrm{a}}$ polytomous regression models for the association between ESR1 polymorphisms and lifetime history of major depressive episodes ${ }^{\mathrm{b}}$ $(\mathrm{N}=3987)$

\begin{tabular}{|c|c|c|c|c|c|c|c|c|c|}
\hline \multirow[b]{2}{*}{ SNP } & \multirow[b]{2}{*}{ Genotype } & \multicolumn{2}{|c|}{$\begin{array}{l}\text { Onset < menopause age, } \\
\text { single episode }(n=106)\end{array}$} & \multicolumn{2}{|r|}{$\begin{array}{l}\text { Onset } \geq \text { menopause age, } \\
\text { single episode }(n=144)\end{array}$} & \multicolumn{2}{|c|}{$\begin{array}{c}\text { Onset }<\text { menopause age, } \\
2 \text { or more episodes }(n=140)\end{array}$} & \multicolumn{2}{|c|}{$\begin{array}{c}\text { Onset } \geq \text { menopause age, } \\
2 \text { or more episodes }(n=76)\end{array}$} \\
\hline & & $N$ & Odds Ratio (95\% CI), $p$ & $N$ & Odds Ratio (95\% CI), $p$ & $N$ & Odds Ratio (95\% CI), $p$ & $N$ & Odds Ratio (95\% CI), $p$ \\
\hline \multirow[t]{3}{*}{ rs9340799 } & $\mathrm{AA}$ & 44 & 1 & 62 & 1 & 46 & 1 & 22 & 1 \\
\hline & GA & 43 & $0.84(0.54-1.31) \quad 0.45$ & 66 & $0.89(0.62-1.29) \quad 0.55$ & 72 & $1.32(0.90-1.95) 0.16$ & 40 & $1.52(0.89-2.59) 0.13$ \\
\hline & GG & 19 & $1.61(0.90-2.89) \quad 0.11$ & 16 & $1.03(0.58-1.84) 0.92$ & 22 & $1.88(1.09-3.25) 0.02$ & 14 & $2.66(1.33-5.33) 0.006$ \\
\hline \multirow[t]{3}{*}{$r s 2234693$} & $\mathrm{TT}$ & 31 & 1 & 42 & 1 & 31 & 1 & 20 & 1 \\
\hline & CT & 48 & $0.88(0.55-1.42) \quad 0.61$ & 76 & $1.01(0.67-1.50) 0.98$ & 79 & $1.44(0.93-2.23) \quad 0.10$ & 32 & $0.89(0.50-1.59) \quad 0.70$ \\
\hline & $\mathrm{CC}$ & 27 & $1.28(0.74-2.22) 0.38$ & 26 & $0.94(0.56-1.58) 0.82$ & 30 & $1.48(0.87-2.51) \quad 0.15$ & 24 & $1.95(1.06-3.61) 0.03$ \\
\hline
\end{tabular}

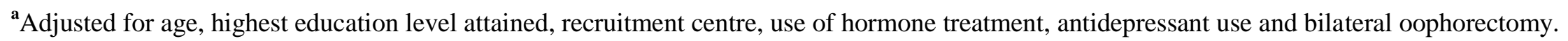

${ }^{\mathbf{b}}$ With reference to women without any major depressive episodes across their lifetime, $\mathrm{n}=3521$ (rs9340799 genotype frequencies: AA=1481, GA=1646,

$\mathrm{GG}=394$; $r$ s2234693 genotype frequencies: $\mathrm{TT}=1076, \mathrm{CT}=1775, \mathrm{CC}=670$ ). 